\title{
Hip arthroplasty: Effective rehabilitation protocols
}

\author{
Artroplastia do quadril: Protocolos de reabilitação eficazes \\ Artroplastia de cadera: Protocolos de rehabilitación efectivos
}

Received: 03/28/2021 | Reviewed: 04/03/2021 | Accept: 04/06/2021 | Published: 04/18/2021

Luan dos Santos Mendes Costa ORCID: https://orcid.org/0000-0001-8767-7986

Federal University of Ceara, Brazil

E-mail: luanmendes@alu.ufc.br

Vanessa Garcia de Lima

ORCID: https://orcid.org/0000-0002-8548-4010

Federal University of Ceara, Brazil

E-mail: vanessa.garcia.lima@gmail.co

Francisco Douglas da Silva Freires Barros

ORCID: https://orcid.org/0000-0002-8699-6990

Federal University of Ceara, Brazil

E-mail: douglasfreiresbarros@gmail.com

Paloma Almeida Pereira

ORCID: https://orcid.org/0000-0003-3959-3408

Federal University of Ceara, Brazil

E-mail: phameida23@gmail.com

Raiana Maria Alves Lima

ORCID: https://orcid.org/0000-0003-1770-0145

Federal University of Ceara, Brazil

E-mail: raianamalima@outlook.com

Ana Karoline Almeida da Silva

ORCID: https://orcid.org/0000-0001-9340-6568 Physical Therapist, Brazil

E-mail: karolinealmeida.fisio@gmail.com

José Carlos Tatmatsu-Rocha

ORCID: https://orcid.org/0000-0003-4900-4857

Federal University of Ceara, Brazil E-mail: tatmatsu@ufc.br

\begin{abstract}
Purpose: To identify the effectiveness of protocols in the functional rehabilitation process in the postoperative treatment of the hip. Methods: This is a systematic review study, composed of 4 blind and independent evaluators divided into three schematic phases. For the construction of this manuscript, the Recommendation Preferred Reporting Items for Systematic Reviews and Meta-Analyzes was applied. The descriptors used were: "rehabilitation", "physical therapy", "arthroplasty" and "hip" using the Boolean operator "AND" between each of them in the indexing bases. Results: Initially, 136 studies were found in LILACS, MEDLINE, MEDCARIB, PAHO-IRIS and WHOLIS, 99 studies in MEDLINE and 08 articles in PEDro. After reading the abstracts, 13 studies were selected, which were carefully analyzed. Discussion: Among the thirteen selected articles, the main clinical effects observed in the evaluated protocols were: improved functionality, quality of life, reduced pain, increased muscle strength. Conclusion: The functional rehabilitation of postoperative hip arthroplasty was significant in protocols that adopted early physical therapy intervention. These protocols resulted in rapid improvement in functionality, reduction of pain and quality of life. These improvements were also seen in protocols applied at home.
\end{abstract}

Keywords: Hip arthroplasty; Physiotherapy; Arthroplasty; Rehabilitation; Hip.

\section{Resumo}

Objetivo: Identificar a eficácia de protocolos no processo de reabilitação funcional no tratamento pós-operatório do quadril. Métodos: Trata-se de um estudo de revisão sistemática, composto por 4 avaliadores cegos e independentes, divididos em três fases esquemáticas. Para a construção deste manuscrito, foi aplicada a Recomendação Preferred Reporting Items for Systematic Reviews e Meta-Analyzes. Os descritores utilizados foram: "reabilitação", "fisioterapia", "artroplastia" e "quadril" utilizando o operador booleano "AND" entre cada um deles nas bases de indexação. Resultados: Inicialmente, foram encontrados 136 estudos no LILACS, MEDLINE, MEDCARIB, PAHOIRIS e WHOLIS, 99 estudos no MEDLINE e 08 artigos na PEDro. Após a leitura dos resumos, foram selecionados 13 estudos, os quais foram analisados criteriosamente. Discussão: Entre os treze artigos selecionados, os principais efeitos clínicos observados nos protocolos avaliados foram: melhora da funcionalidade, qualidade de vida, redução da dor, 
aumento da força muscular. Conclusão: A reabilitação funcional do pós-operatório de artroplastia de quadril foi significativa em protocolos que adotaram intervenção fisioterapêutica precoce. Esses protocolos resultaram em rápida melhora da funcionalidade, redução da dor e qualidade de vida. Essas melhorias também foram observadas em protocolos aplicados em casa.

Palavras-chave: Artroplastia de quadril; Fisioterapia; Artroplastia; Reabilitação; Quadril.

\section{Resumen}

Objetivo: Identificar la eficacia de los protocolos en el proceso de rehabilitación funcional en el postoperatorio de cadera. Métodos: Se trata de un estudio de revisión sistemática, compuesto por 4 evaluadores ciegos e independientes divididos en tres fases esquemáticas. Para la construcción de este manuscrito, se aplicó la Recomendación de Ítems de Informe Preferidos para Revisiones Sistemáticas y Metanálisis. Los descriptores utilizados fueron: "rehabilitación", "fisioterapia", "artroplastia" y "cadera" utilizando el operador booleano "Y" entre cada uno de ellos en las bases de indexación. Resultados: Inicialmente se encontraron 136 estudios en LILACS, MEDLINE, MEDCARIB, PAHO-IRIS y WHOLIS, 99 estudios en MEDLINE y 08 artículos en PEDro. Luego de la lectura de los resúmenes, se seleccionaron 13 estudios, los cuales fueron cuidadosamente analizados. Discusión: Entre los trece artículos seleccionados, los principales efectos clínicos observados en los protocolos evaluados fueron: mejora de la funcionalidad, calidad de vida, reducción del dolor, aumento de la fuerza muscular. Conclusión: La rehabilitación funcional de la artroplastia de cadera postoperatoria fue significativa en los protocolos que adoptaron la intervención de fisioterapia temprana. Estos protocolos dieron como resultado una rápida mejora en la funcionalidad, reducción del dolor y calidad de vida. Estas mejoras también se observaron en los protocolos aplicados en casa.

Palabras clave: Artroplastia de cadera; Fisioterapia; Artroplastia; Rehabilitación; Cadera.

\section{Introduction}

The coxofemoral joint is an enarthrosis that has great freedom of movement, which is provided by the concave spherical shape of the femoral head and the convex hemispherical fossa of the acetabulum. The movement of the hip joint must occur without difficulty and without the presence of pain, possibly reaching large amplitudes. However, if the range of motion (ROM) presents pain or limitations, these can become progressive, and may gradually cause an impact on the individual's quality of life (Tejedor, 2015).

Hip osteoarthritis is one of the complications that can generate localized, continuous pain in that joint. The highest incidence occurs in female patients over 40 years old, and may be caused by factors such as trauma, necrosis of the femoral head, rheumatic and childhood diseases (Almeida et al., 2016). Surgical treatment for advanced stages of osteoarthritis must take into account age, cause, activities to be performed, ROM and bilateral or not condition. Three types of procedures can be indicated: those that totally restrict movement; those who preserve articulation; those that replace the joint (Winther et al., 2018).

The procedure of replacing the joint with a prosthesis is called arthroplasty. Total Hip Arthroplasty (THA) is indicated when the conservative treatment fails and is understood as an effective procedure that provides better quality of life for patients, as it reduces pain and improves the functional capacity of the hip joint. THA is described as a surgery that replaces the affected hip with a metallic or plastic prosthesis, in favor of a safer and more comfortable joint. The choice of the type of prosthesis is determined according to the disease that led to the surgery, the patient's age and its activities, which may vary between cemented, non-cemented or hybrid prostheses, which will have an impact on the type of rehabilitation of the patient (Rosenlund et al., 2017). The life expectancy of the population has been increasing and as a result, THA will become even more frequent in the coming decades, as this procedure has been achieving good results. According to Ferreira et al. (2018), by the year 2021, the number of indications for THA will increase by $40 \%$. It is important to consider the increase in life expectancy of the population in relation to this increase in THA indications, and, with this, the inherent problems of this age group, such as fractures of the proximal femur, among which we highlight the Neck of Femur (NOF) fractures, revealing a greater weight of chronic degenerative diseases, including joint pathologies (Ferreira et al., 2018).

After surgery, caution is required to improve the mobility of these patients and decrease complications. Postoperative care is needed, among which, physiotherapy stands out. This therapeutic approach acts directly on the first motor activities of this patient, such as: sitting, walking around the bed, indicating auxiliary devices such as the walker, for example. Being the first 
professional to remove the patient from the bed, he will provide guidance on the correct performance of exercises to be performed, the adaptations that may assist in the patient's mobility and functionality (Ferreira et al., 2018). Physiotherapy interventions must be present preoperatively, on the day of surgery and in the postoperative period (Cavill et al., 2016).

In view of the scenario of different individuals who underwent hip arthroplasty, we sought to list which physiotherapy procedures were most effective in the rehabilitation programs adopted by professionals and directed to their patients.

\section{Methodology}

This is a systematic review article composed of blind and independent evaluators, and divided into the three schematic phases described below. For the construction of this manuscript, the recommendation PRISMA (Preferred Reporting Items for Systematic Reviews and Meta-Analyzes) (Galvão et al., 2015) was applied. The objective of this manuscript was to identify the efficacy of functional rehabilitation protocols in the hip postoperative treatment process. The phases described below sought for studies that would elucidate the answer to the question PICO: What behaviors adopted by physiotherapists in the postsurgical rehabilitation programs for hip arthroplasty were effective?. For the purposes of methodological analysis of the selected studies, the Jadad Scale (Jadad et al., 1996) was applied, scoring between 0 and 5 with criteria in the axes of randomization, blinding and loss of sampling.

Phase I: Searches were performed for the keywords Rehabilitation AND physical therapy AND arthroplasty AND hip, on the following bases: Virtual Health Library (VHL), Medical Literature Analysis and Retrieval System Online (PubMed/Medline) Physiotherapy Evidence Database (PEDro), between October and November 2019. The following inclusion criteria were applied: clinical trial studies, available in full, with a sample composed of human beings, published in Portuguese or English between the years 2009 and 2019. Exclusion criteria were: studies that did not present the physiotherapeutic conduct used, study with animals, reviews, and studies that did not present at least two of the following terms, in their titles and / or abstracts: Rehabilitation; physical therapy; arthroplasty; hip;

Phase II: The LSMC and PAP performed the screening of the results with the reading of titles and abstracts;

Phase III: The FDSFB and RMAL performed the full reading of the studies chosen in the LSMC and PAP in phase II. Articles in agreement between FDSFB and RMAL were chosen to compose this manuscript.

\section{Results and Discussion}

Phase I resulted in 136 studies in the Virtual Health Library (VHL) composed of the LILACS, MEDLINE, MEDCARIB, PAHO-IRIS and WHOLIS databases, 99 studies in PubMed/Medline and 08 articles in PEDro, including 01 duplicated study. Phase II resulted in 68 studies selected by the evaluator LSM, 62 by the PAP and 62 studies were in agreement between both evaluators. Phase III, definitive for the final composition of N, resulted in 15 studies selected by the evaluator FDSFB and 17 studies selected by the evaluator RMAL; of these, 13 studies were in agreement by both evaluators and were chosen to compose this review. 
Figure 1. Flowchart of searches about the proposed theme. The PRISMA recommendation.

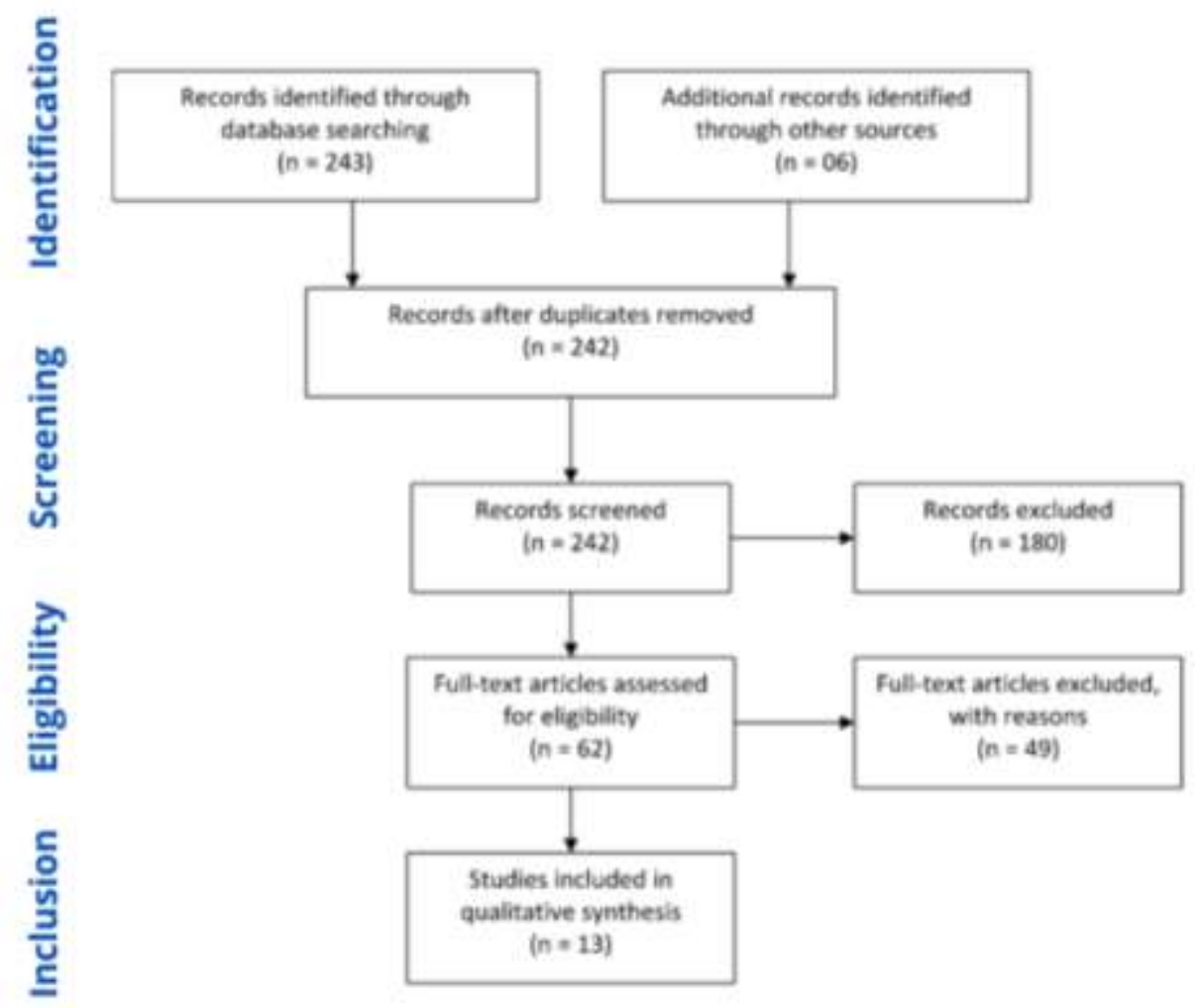

Source: Authors. Made using free Canva software, web version.

The methodological quality of the studies was analyzed using the Jadad scale (Jadad et al., 1996), in Frame 1., scoring each between 0 and 5. Studies with a score below 3 are considered to be of low methodological quality. The scale comprises the following specific criteria: description and method of randomization, description and method of blinding and sample loss. The frame below represents the score obtained for each study.

Frame 1. Methodological analysis of the studies according to the JADAD scale.

\begin{tabular}{|l|c|c|c|c|c|}
\hline \multicolumn{7}{|l|}{ JADAD SCALE } & $\begin{array}{c}\text { Was the study } \\
\text { described as } \\
\text { randomized? }\end{array}$ & $\begin{array}{c}\text { Was the } \\
\text { study } \\
\text { Itescribed } \\
\text { as double } \\
\text { blind? }\end{array}$ & $\begin{array}{c}\text { Does the study } \\
\text { present a } \\
\text { description of } \\
\text { exclusions and } \\
\text { losses? }\end{array}$ & $\begin{array}{c}\text { Has the } \\
\text { randomization } \\
\text { method been } \\
\text { described and } \\
\text { appropriate? }\end{array}$ & $\begin{array}{c}\text { Has the blinding } \\
\text { method been described } \\
\text { and appropriate? }\end{array}$ \\
\cline { 1 - 5 } STUDIES AND SCORES & 0 & 0 & 0 & 0 & 0 \\
\hline $\begin{array}{l}\text { Musumeci (et. al., 2018). } \\
\text { TOTAL SCORE: 0 }\end{array}$ & 1 & 1 & 1 & 0 & 0 \\
\hline $\begin{array}{l}\text { Coulter (et. al., 2017). } \\
\text { TOTAL SCORE: 3 }\end{array}$ & 1 & 1 & 0 & 1 & 1 \\
\hline $\begin{array}{l}\text { Barker (et. al., 2013). } \\
\text { TOTAL SCORE: 4 }\end{array}$ & 1 & 1 & 1 & 1 & 0 \\
\hline $\begin{array}{l}\text { Stockton (et. al., 2009). } \\
\text { TOTAL SCORE: 5 }\end{array}$ & & & & & 0 \\
\hline
\end{tabular}




\begin{tabular}{|l|c|c|c|c|c|}
\hline $\begin{array}{l}\text { Busato (et.al., 2016). } \\
\text { TOTAL SCORE: 5 }\end{array}$ & 1 & 1 & 1 & 1 & 1 \\
\hline $\begin{array}{l}\text { Tsukagoshi (et. al., 2012). } \\
\text { TOTAL SCORE: } 3\end{array}$ & 0 & 0 & 1 & 1 & 1 \\
\hline $\begin{array}{l}\text { Nakanowatari (et. al., 2016). } \\
\text { TOTAL SCORE: } 3\end{array}$ & 1 & 0 & 0 & 1 & 1 \\
\hline $\begin{array}{l}\text { Villafañe (et. al., 2016). } \\
\text { TOTAL SCORE: } 4\end{array}$ & 0 & 1 & 1 & 1 & 0 \\
\hline $\begin{array}{l}\text { Okoro (et.al., 2016). } \\
\text { TOTAL SCORE: 5 }\end{array}$ & 0 & 0 & 1 & 1 & 0 \\
\hline $\begin{array}{l}\text { Judd (et. al., 2016). } \\
\text { TOTAL SCORE: } 2\end{array}$ & 0 & 0 & 0 & 0 & 1 \\
\hline $\begin{array}{l}\text { Juliano (et.al., 2010). } \\
\text { TOTAL SCORE: } 0\end{array}$ & 1 & 0 & 1 & 1 & 1 \\
\hline $\begin{array}{l}\text { Husby (et. al., 2011). } \\
\text { TOTAL SCORE: 5 }\end{array}$ & 1 & 1 & 1 & 0 \\
\hline $\begin{array}{l}\text { Larsen (et. al., 2009). } \\
\text { TOTAL SCORE: } 3\end{array}$ & & 0 & 1 & 1 \\
\hline
\end{tabular}

Source: Authors. Made using Microsoft 365 ${ }^{\circledR}$ Word software. Data extracted from qualitative analyzes after screening studies in the databases.

In general, only three studies were classified as of low methodological quality (Musumeci et al., 2018; Jud et al., 2016; Juliano et al., 2011), where two of these did not score according to the scale sieve (Musumeci et al., 2018; Juliano et al., 2011). In contrast, 10 of the 13 studies showed methodological quality considered high by the instrument, 4 of them received maximum scores. The results obtained from the methodological analysis indicate the quality of the studies included in this manuscript.

The 13 studies selected for this systematic review study were organized in the following summary in Frame 2. composed of the following items: author, year of publication of the study, sample, physiotherapeutic conduct and results obtained.

Frame 2. Summary of the main findings of the selected studies.

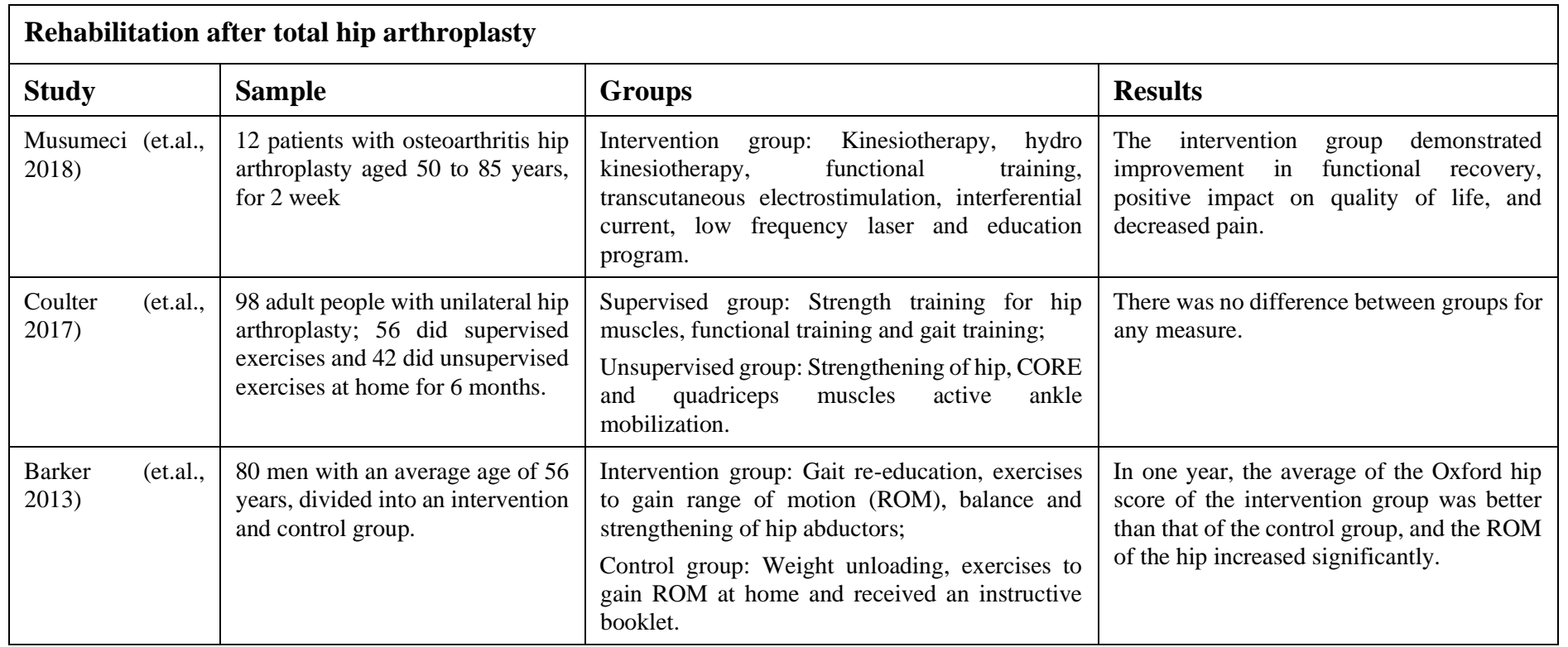




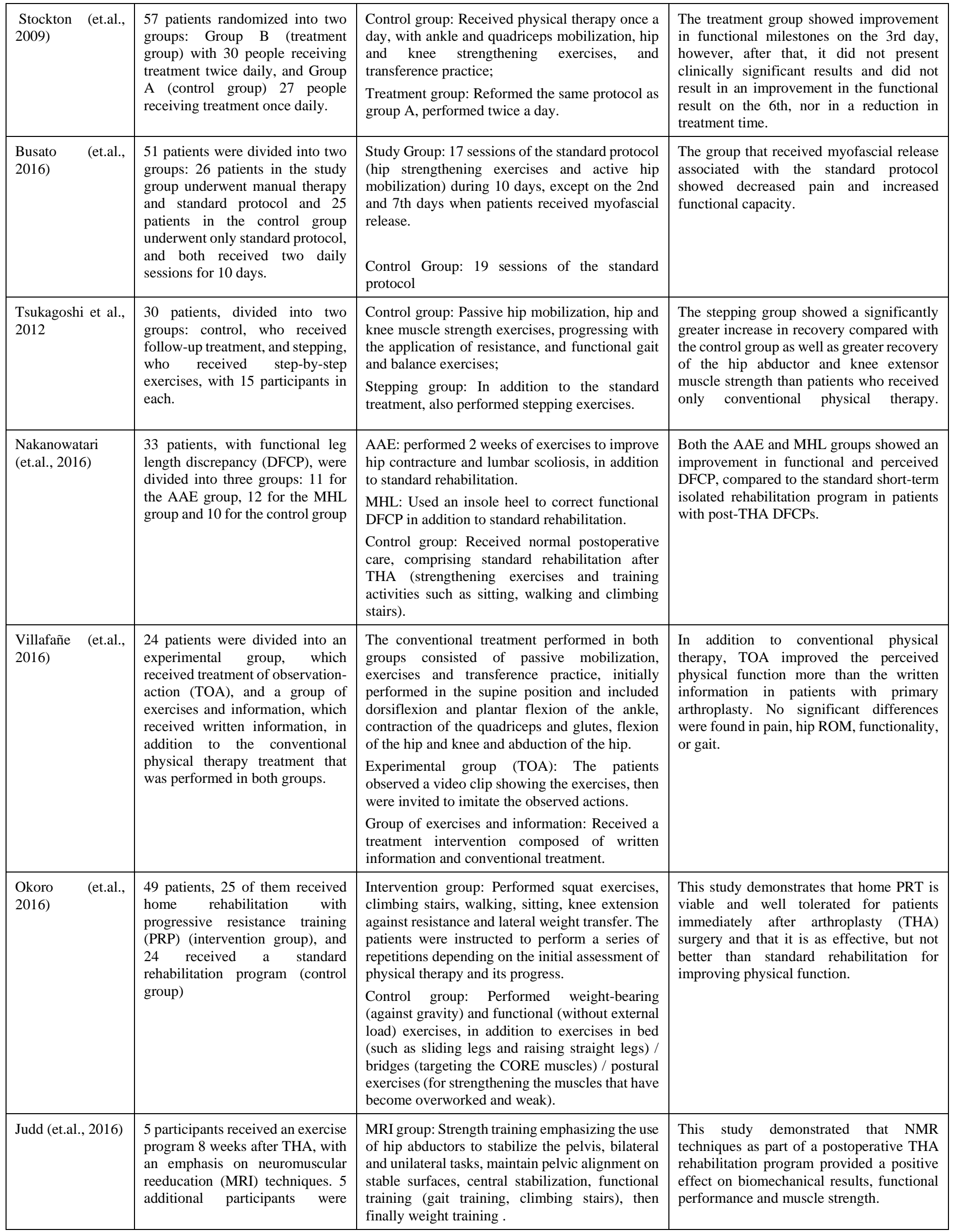




\begin{tabular}{|c|c|c|c|}
\hline & $\begin{array}{l}\text { supervised and followed for } \\
\text { comparison. }\end{array}$ & $\begin{array}{l}\text { Control group: Education on exercises received } \\
\text { during hospitalization, activities to improve } \\
\text { ROM, flexibility and isometric muscle training. } \\
\text { As well as education on functional training and } \\
\text { safety for activities of daily living. }\end{array}$ & \\
\hline $\begin{array}{l}\text { Juliano (et.al., } \\
\text { 2011) }\end{array}$ & $\begin{array}{l}408 \text { patients of ages between } 27 \\
\text { and } 83 \text { years, equally divided into } \\
\text { DOS group (Day of Surgery) and } \\
\text { POD1 group (Post-op Day 1). }\end{array}$ & $\begin{array}{l}\text { DOS Group: The patients started physiotherapy } \\
\text { on the day of the surgery, basing the length of stay } \\
\text { in } 3 \text { days; } \\
\text { POD1 Group: The patients started physiotherapy } \\
\text { on the first postoperative day, based on the length } \\
\text { of stay in } 4 \text { days; } \\
\text { The two groups used as clinical guidelines: } \\
\text { assessment, posture change, bedside exercises, } \\
\text { weight transfer, gait training, sit-ups, stairs } \\
\text { training, strengthening and instructions for } \\
\text { postoperative total hip arthroplasty. }\end{array}$ & $\begin{array}{l}\text { The patients in the DOS group reduced the } \\
\text { length of stay by an average of } 0.21 \text { days, } \\
\text { compared to the POD1 group, without } \\
\text { compromising the achievement of } \\
\text { functional milestones. }\end{array}$ \\
\hline $\begin{array}{l}\text { Larsen (et.al., } \\
\text { 2009) }\end{array}$ & $\begin{array}{l}87 \text { patients treated with total hip } \\
\text { arthroplasty or unicompartmental } \\
\text { or total knee arthroplasty. } \\
\text { Randomized into a standard } \\
\text { intervention group and an } \\
\text { accelerated intervention group. }\end{array}$ & $\begin{array}{l}\text { Standard intervention group: Hospitalization the } \\
\text { day before surgery. Mobilization and exercises } \\
\text { started on the 1st postoperative day. Individual } \\
\text { and gradual mobilization according to the } \\
\text { patient's tolerance. } 4 \text { hours of mobilization per } \\
\text { day. } \\
\text { Accelerated intervention group: Hospitalization } \\
\text { on the day of surgery. Mobilization and exercises } \\
\text { started on the day of the surgery. Intensive } \\
\text { mobilization of the patients in teams after pre- } \\
\text { defined daily goals. } 8 \text { hours of mobilization per } \\
\text { day. }\end{array}$ & $\begin{array}{l}\text { The accelerated intervention dominates the } \\
\text { standard intervention when used for patients } \\
\text { treated with hip arthroplasty. }\end{array}$ \\
\hline
\end{tabular}

Source: Authors. Made using Microsoft 365® Word software. Data extracted from qualitative analyzes after screening studies in the databases.

After reading the selected articles, listed in Frame 2., it was noticed that there was no consensus regarding the protocols to be used in the postoperative period of hip arthroplasty, despite the good scores on the Jadad Scale, listed in Frame 1., of the selected articles. Among the thirteen selected articles, the main clinical effects observed in the evaluated protocols were: Improved functionality, quality of life, reduced pain and increased muscle strength. However, in this review, we observed that there is a need for standardization regarding the type of intervention, frequency and duration of protocols for rehabilitation after hip arthroplasty. Additionally, we were able to observe that there were no significant differences in the results between the interventions carried out in offices and clinics, and the activities carried out at home, indicating that it would be beneficial and safe for patients to be recommended the practice of a complementary exercise protocol by the physiotherapists who accompany them.

This home practice was observed in the supervised versus unsupervised rehabilitation process in 98 individuals, qualified for the THA postoperative rehabilitation program. There were no statistically relevant differences in these individuals, between the groups that carried out the program in a supervised manner and the group that carried out the program independently 
(Coulter et al., 2017). Therefore, it is possible to take into account that by raising awareness and guiding the patient in an appropriate way, and offering professional support according to the degree of commitment of the individual, it is possible to reduce the costs of physiotherapy sections by offering greater independence for the patient to perform exercises in their own residence. The findings obtained from a study carried out with 49 individuals after THA corroborate the results above, in which the rehabilitation program at home was as effective as the program carried out in a supervised manner (Okoro et al., 2016). On the other hand, the findings obtained in the study by Stockton (et.al., 2009), when analyzing the results of their sample composed of 80 male individuals, they point out significantly higher values for the gain in range of motion in the supervised group when compared to the control group (Stockton et al., 2009).

Juliano (et.al., 2010) divided the participants into 2 Groups: DOS Group, in which the patients started physiotherapy on the day of surgery, basing the length of stay in 3 days; and Group POD1, in which patients started physiotherapy on the first postoperative day, basing the length of stay in 4 days. The results were that the patients in the DOS group reduced the length of stay by an average of 0.21 days compared to the POD1 group, without compromising the achievement of functional milestones (Juliano et al., 2011). These results indicate that it is feasible and safe to perform maximum strength training one week after THA (Husby et al., 2009). Such data corroborate the findings of another study (Larsen et al., 2009), which demonstrated that patients who performed an accelerated intervention protocol, with mobilization and exercises starting on the day of surgery, the intensive mobilization of the patients in teams after pre-defined daily goals achieved a significant improvement. These results also proved to be effective in home protocols, where it was possible to observe patients' tolerance immediately after arthroplasty surgery (THA), showing that home proposals can be effective (Okoro et al., 2016).

From a social perspective, the cost-effectiveness of an accelerated intervention (rapid intervention that is based on perioperative care and rehabilitation) was compared with the standard protocol, after total hip or knee arthroplasty (Larsen et al., 2009). In this study, the standard protocol group received the procedure information separately on the day of admission, they were hospitalized the day before surgery and began rehabilitation on the first day after the operation. Individual mobilization was performed gradually according to the patient's tolerance, counting 4 hours of mobilization in the standard group, and they passed on the information of the procedure of the groups at a consultation before hospitalization, which happened on the day of the surgery. Standard group had the collaboration of several nursing and occupational therapy professionals to provide support for physical exercises and joint mobilization. The accelerate group had a nurse leader with other professionals (physical therapists and occupational therapy). Joint mobilization and exercises in this group started on the same day of the chirurgical intervention (T0), with intensive exercises and goals set daily, accounting for eight hours a day. At the end of the study, it was noted that the accelerated intervention showed better cost-effectiveness compared to the standard intervention, when implemented after total hip arthroplasty (Larsen et al., 2009). These findings may indicate a shorter duration of the rehabilitation process and an optimization of work teams.

This rehabilitation process is commonly performed in environments such as hospitals, outpatient clinics and at home. However, Musumeci (et.al., 2018) proposed the use of a multimodal thermal rehabilitation program in association with a spa center. Their findings demonstrated good results in relieving pain, improving motor and functional capacity, in addition to improving the quality perceived by patients. The program consisted of six sessions with $2 \mathrm{~h} 30$ hours, during two weeks. of treatment, combining an educational program, hydro kinesiotherapy, and exercises on the ground with passive joint mobilization and functional training for two weeks (Musumeci et al., 2018).

Busato (et.al., 2016) and Stockton (et.al., 2009) presented evidence that pointed to a functional improvement in postsurgical patients treated with manual therapy associated with the traditional physical therapy program (Busato et al., 2016, Stockton et al., 2009). In these studies, the manipulation of the fascia was effective in reducing pain, increasing ROM in hip movements and muscle capacity, along with the standard protocol. In the study by Busato et al. (Busato et al., 2016) the protocol 
established 2 daily sessions, which resulted in a tendency to achieve functional milestones earlier (such as independence in mobility and transfer), but did not result in a decrease in the length of stay for early discharge. In another study (Juliano et al., 2011), it was examined whether the beginning of physiotherapy on the day of surgery reduces the length of stay without compromising functional results after total hip arthroplasty. The first group (POD1) was recommended physical therapy starting on the 1st day after surgery and basing the length of stay in 4 days. The second group (DOS) was indicated the beginning of physiotherapeutic treatment on the day of surgery with a stay of 3 days. Both groups had the following as clinical conducts: assessment, changing postures, exercises at the bedside, weight transfer, gait training, sit-up and stairs training, strengthening, and guidelines for the post-OP of hip arthroplasty (Juliano et al., 2011). It was found that the beginning of physiotherapy on the day of surgery resulted in a decrease in the length of hospital stay of 0.21 days compared to the beginning on the 1st day after OP (Juliano et al., 2011), thus reinforcing the evidence that early physical therapy intervention is an important ally in the costbenefit ratio in hospital admissions.

This cost-benefit ratio and precociousness of the rehabilitation process can be influenced by the re-education of patients' gait. In this sense, a study compared patients who underwent THA that received maximum strength training in addition to conventional rehabilitation, with another group that received only conventional rehabilitation (Husby et al., 2009). In conventional rehabilitation, the patients were submitted to sling exercises therapy for the hip movements, avoiding rotations with low or no resistance exercises (12-15 repetitions) and exercises in the water when the sutures were removed. They performed that protocol for 1 hour, 5 times a week, for 4 weeks (Husby et al., 2009). For the intervention group in addition to the conventional rehabilitation program, patients received 10 minutes of stationary cycling and 4 sets of 5 maximum repetitions of leg press and hip abduction with the operated leg. 5 times a week for 4 weeks (Husby et al., 2009). The results of the study show that maximum strength training was adequate for postoperative THA treatment, since there was an improvement in strength and power in the intervention group compared to the control group. However, there were no significant improvements in gait or quality of life between the groups after the interventions (Husby et al., 2009).

Regarding the use of steps in the rehabilitation process, in a sample composed of 30 post-THA individuals divided into two control and stepping groups, 15 patients each, it was observed that the use of steps in the rehabilitation process was significantly relevant for recovery of the hip and knee abductor and extensor muscle strength compared with the patients who only received conventional physical therapy (Tsukagoshi et al., 2012). The control group was monitored for passive hip mobilization, hip and knee muscle strength exercises, progressing with the application of resistance, and functional gait and balance exercises. The stepping group, in addition to receiving the standard post-THA rehabilitation program, was subjected to a sequence of exercises using steps (Tsukagoshi et al., 2012). The application of exercises related to the use of steps associated with neuromuscular reeducation (NMR) in 10 individuals corroborates the described findings, by elucidating that NMR techniques as part of a postoperative THA rehabilitation program provided a positive effect on biomechanical results, functional performance and muscle strength according to the author of the study (Judd et al., 2016).

Similar results were found regarding the improvement of functionality in the studies carried out by Musumeci et al. (Musumeci et al., 2018), where the intervention group associated a Kinesiotherapy, hydro kinesiotherapy, functional training, transcutaneous electrostimulation, interferential current, low frequency laser and education program protocol. In this group, there was an improvement in functionality, a decrease in pain and an improvement in quality of life. Barker (et.al., 2013) showed in their results that in one year with the protocol used, an improvement in the average of the Oxford hip score of the intervention group was observed better than that of the control group, and the hip amplitude increased significantly.

Some studies showed variations in their protocols, making it difficult to standardize the analysis of this review. As examples, we have works such as those by Busato (et.al., 2016) where a group that received myofascial release associated with the standard protocol showed decreased pain and increased functional capacity. Tsukagoshi (et.al., 2012) observed in their results 
that the control group showed greater recovery of the hip abductor and knee extensor muscle strength than patients who received only conventional physical therapy. Nakanowatari (et.al., 2016) used a protocol that divided participants between control groups, AAE group, who performed 2 weeks of exercises to improve hip contracture and lumbar scoliosis, in addition to standard rehabilitation, and the MHL group who used an insole heel to correct the Functional DFCP in addition to standard rehabilitation. This author pointed out that both the AAE group and the MHL group showed an improvement in functional and perceived DFCP, compared to the standard short-term isolated rehabilitation program in patients with post-THA DFCPs. Judd (et.al., 2016) found an improvement in patients that used NMR techniques as part of a postoperative THA rehabilitation program, it provided a positive effect on biomechanical results, functional performance and muscle strength.

In contrast to most articles that reported improvements and clinical gains, some authors did not identify such gains. Stockton (et.al., 2009) reported that in his treatment group there was an improvement in functional milestones on the 3rd day, although after that period, there were no clinically significant results and it did not result in an improvement in the functional outcome on the 6th day, nor a reduction in the time of treatment. Other authors such as Coulter (et.al., 2017) relate that in his supervised group there was strength training for the hip muscles, functional training and gait training, and in the unsupervised group, strengthening of the muscles of the hip, the CORE and the quadriceps active ankle mobilization, there was no difference between groups for no measure. Finally, Villafañe (et.al., 2016) described that of their groups, the TOA group was the one that had an improvement in perceived physical function more than the information written in patients in the THA group. No significant differences were found in pain, hip ROM, functionality or gait (Villafañe et al., 2016).

\section{Final Considerations}

Based on the results of the analyzed studies, taking into account their methodological quality, it is possible to conclude that the protocols that address early intervention in the functional rehabilitation process showed better results in terms of rapid improvement in functionality, reduction of pain and quality of life.

In this manuscript, it was observed that there is no single effective program in this process, but a standard that involves functional aspects of techniques and exercises that must be widely addressed in a different way for each individual.

The suggestion is when preparing and/or prescribing a rehabilitation protocol, the professional should address functional aspects pointed out by this manuscript, observing the peculiarities of each patient. In addition, it would be important to standardize the criteria to be used for the prescription of the exercises, such as frequency, duration, periodicity and number of repetitions of the exercises, since it was observed in this study that the authors who publish in the area end up neglecting these data, making it difficult to standardize a protocol based on the evidence collected in recent years.

It was also observed that the applicability of home protocol programs emerges as a promising alternative in the functional rehabilitation of patients with a postoperative profile of hip arthroplasty. However, there is not enough evidence for this modality to replace rehabilitation with the presence of a trained professional, in order to improve physical function. Therefore, it needs new studies to prove or refute this modality.

\section{Acknowledgments}

The authors are grateful to the Center for Research and Technological Innovations in Human Rehabilitation (INOVAFISIO), linked to the Physiotherapy Department of the Faculty of Medicine of the Federal University of Ceará.

\section{References}

Almeida, F. D. J. F., Carvalho, C. A. D., Fonsêca, P. C. D. A., Nina, V. J. D. S., \& Mochel, E. G. (2016). Application of kinesiotherapy and electrothermotherapy in the treatment of elderly with knee osteoarthrosis: a comparative study. Fisioterapia em Movimento, 29(2), $325-334$. 
Barker, K. L., Newman, M. A., Hughes, T., Sackley, C., Pandit, H., Kiran, A., \& Murray, D. W. (2013). Recovery of function following hip resurfacing arthroplasty: a randomized controlled trial comparing an accelerated versus standard physiotherapy rehabilitation programme. Clinical rehabilitation, 27(9), $771-784$.

Busato, M., Quagliati, C., Magri, L., Filippi, A., Sanna, A., Branchini, M., \& Stecco, A. (2016). Fascial manipulation associated with standard care compared to only standard postsurgical care for total hip arthroplasty: a randomized controlled trial. $P M \& R, 8(12), 1142-1150$.

Cavill, S., McKenzie, K., Munro, A., McKeever, J., Whelan, L., Biggs, L., \& Haines, T. P. (2016). The effect of prehabilitation on the range of motion and functional outcomes in patients following the total knee or hip arthroplasty: A pilot randomized trial. Physiotherapy theory and practice, 32(4), 262-270.

Coulter, C., Perriman, D. M., Neeman, T. M., Smith, P. N., \& Scarvell, J. M. (2017). Supervised or unsupervised rehabilitation after total hip replacement provides similar improvements for patients: a randomized controlled trial. Archives of physical medicine and rehabilitation, 98(11), $2253-2264$.

Ferreira, M. D. C., Oliveira, J. C. P., Zidan, F. F., Franciozi, C. E. D. S., Luzo, M. V. M., \& Abdalla, R. J. (2018). Artroplastia total de joelho e quadril: a preocupante realidade assistencial do Sistema Único de Saúde brasileiro. Revista Brasileira de Ortopedia, 53(4), 432-440.

Galvão, T. F., Pansani, T. D. S. A., \& Harrad, D. (2015). Principais itens para relatar Revisões sistemáticas e Meta-análises: A recomendação PRISMA. Epidemiologia e Serviços de Saúde, 24, 335-342.

Husby, V. S., Helgerud, J., Bjørgen, S., Husby, O. S., Benum, P., \& Hoff, J. (2009). Early maximal strength training is an efficient treatment for patients operated with total hip arthroplasty. Archives of physical medicine and rehabilitation, 90(10), 1658-1667.

Jadad, A. R., Moore, R. A., Carroll, D., Jenkinson, C., Reynolds, D. J. M., Gavaghan, D. J., \& McQuay, H. J. (1996). Assessing the quality of reports of randomized clinical trials: is blinding necessary? Controlled clinical trials, 17(1), 1-12.

Judd, D. L., Winters, J. D., Stevens-Lapsley, J. E., \& Christiansen, C. L. (2016). Effects of neuromuscular reeducation on hip mechanics and functional performance in patients after total hip arthroplasty: a case series. Clinical Biomechanics, 32, 49-55.

Juliano, K., Edwards, D., Spinello, D., Capizzano, Y., Epelman, E., Kalowitz, J., \& Ghomrawi, H. (2011). Initiating physical therapy on the day of surgery decreases length of stay without compromising functional outcomes following total hip arthroplasty. HSS Journal@, 7(1), 16-20.

Larsen, K., Hansen, T. B., Thomsen, P. B., Christiansen, T., \& Søballe, K. (2009). Cost-effectiveness of accelerated perioperative care and rehabilitation after total hip and knee arthroplasty. JBJS, 91(4), 761-772.

Musumeci, A., Pranovi, G., \& Masiero, S. (2018). Patient education and rehabilitation after hip arthroplasty in an Italian spa center: a pilot study on its feasibility. International journal of biometeorology, 62(8), 1489-1496.

Nakanowatari, T., Suzukamo, Y., \& Izumi, S. I. (2016). The effectiveness of specific exercise approach or modifiable heel lift in the treatment of functional leg length discrepancy in early post-surgery inpatients after total hip arthroplasty: A randomized controlled trial with a PROBE design. Physical therapy research, 19(1), 39-49.

Okoro, T., Whitaker, R., Gardner, A., Maddison, P., Andrew, J. G., \& Lemmey, A. (2016). Does an early home-based progressive resistance training program improve function following total hip replacement? Results of a randomized controlled study. BMC musculoskeletal disorders, 17(1), 1-9.

Rosenlund, S., Broeng, L., Holsgaard-Larsen, A., Jensen, C., \& Overgaard, S. (2017). Patient-reported outcome after total hip arthroplasty: comparison between lateral and posterior approach: A randomized controlled trial in 80 patients with 12-month follow-up. Acta orthopaedica, 88(3), $239-247$.

Stockton, K. A., \& Mengersen, K. A. (2009). Effect of multiple physiotherapy sessions on functional outcomes in the initial postoperative period after primary total hip replacement: a randomized controlled trial. Archives of physical medicine and rehabilitation, 90(10), 1652-1657.

Tejedor Zarzuela, M. H. (2015). Fisioterapia en prótesis total de cadera. Revisión bibliográfica.

Tsukagoshi, R., Tateuchi, H., Fukumoto, Y., Okumura, H., \& Ichihashi, N. (2012). Stepping exercises improve muscle strength in the early postoperative phase after total hip arthroplasty: a retrospective study. American journal of physical medicine \& rehabilitation, 91(1), 43-52.

Villafañe, J. H., Pirali, C., Isgrò, M., Vanti, C., Buraschi, R., \& Negrini, S. (2016). Effects of action observation therapy in patients recovering from total hip arthroplasty arthroplasty: a prospective clinical trial. Journal of chiropractic medicine, 15(4), 229-234.

Winther, S. B., Foss, O. A., Husby, O. S., Wik, T. S., Klaksvik, J., \& Husby, V. S. (2018). A randomized controlled trial on maximal strength training in 60 patients undergoing total hip arthroplasty: Implementing maximal strength training into clinical practice. Acta orthopaedica, 89(3), $295-301$.

Wu, C., Wu, Z., Yang, L., Zhu, W., Zhang, M., Zhu, Q., \& Pan, Y. (2018). Evaluation of the clinical outcomes of telehealth for managing diabetes: a PRISMAcompliant meta-analysis. Medicine, 97(43). 